\title{
Digihumanitaariast kultuuriandmete analüüsini
}

\author{
INDREK IBRUS, MAXIMILIAN SCHICH, MAREK TAMM
}

\section{Digihumanitaaria tõus ja langus}

Digihumanitaaria (ingl digital humanities) on üks humanitaarteaduste kõige edukamaid lendsõnu viimasel viieteistkümnel aastal. Selle kiiluvees on tehtud ja tehakse mitmekesist ja sisukat uurimistööd ning võib julgelt tõdeda, et digihumanitaaria on kujundanud humanitaarteaduste praegust palet enam kui ükski teine uus lähenemine. Selle eduloo taustal ei saa jätta siiski tähelepanuta, et digihumanitaaria on mitmes mõttes probleemne nimetus. Väidame käesolevas artiklis, et kuigi see on olnud väga vajalik lipukiri humanitaarse teadustöö uuendamisel sajandi esimesel kahel kümnendil, siis praeguseks on nimetus oma potentsiaali suuresti ammendanud ning on aeg liikuda edasi täpsemate ja konkreetsemate mõistete ning lähenemiste poole.

Milles seisneb digihumanitaaria probleemsus? Kui alustada kõige üldisemast, siis kummitavad digihumanitaariat algusest peale defineerimisraskused. Pea kaks kümnendit väldanud vaidlusi ${ }^{1}$ iseloomustab kõige paremini see, kuidas 2004. aastal soovitas valdkonna alustrajav koguteos, „Digihumanitaaria käsiraamat” käsitleda „digihumanitaariat kui omaette distsipliini" (Schreibman jt 2004: xxiii). Kui aga samad autorid koostasid tosin aastat hiljem koguteose täielikult ümbertöötatud versiooni pealkirjaga „Uus digihumanitaaria käsiraamat”, siis tunnistasid nad enesekriitiliselt, et „jääb vaieldavaks, kas digihumanitaariat tuleb käsitada kui „omaette distsipliini” või pigem kui omavahel seotud meetodite komplekti” (Schreibman jt 2016: xvii). Vaatamata paljudele katsetele pole digihumanitaarid tänini jõudnud enam-vähemgi konsensusliku arusaamani, kuidas uut valdkonda määratleda ja piiritleda. Väga ilmekas on Jason Heppleri koostatud veebileht What Is Digital Humanities?, mis koondab kokku 817 (sic!) digihumanitaaria definitsiooni aastatest 2009-2014.

Üksikasjalikumaks minnes on õigupoolest problemaatilised selle sõnaühendi mõlemad osapooled: digi ja humanitaaria. Kui alustada viimasest, siis on paradoksaalsel moel tegemist ühtaegu nii liiga avara kui ka liiga kitsa nimetusega, et seda mõttekalt kasutada. Liiga avaraga selles tähenduses, et tänapäeval on vähe teadlasi - kui üldse -, kes identifitseerivad ennast humanitaarteadlasena üldiselt. See on liiga lai katusmõiste, et kirjeldada konkreetset uurimisvaldkonda. Mõistagi saab öelda, et kellegi uurimisvald jääb humanitaariasse, ent sellele peab järgnema selgitus, millisesse humanitaaria valdkonda täpsemalt. Maailmas on vähe humanitaarteaduste professuure, seega ei ole mõistlik neid luua ka digihumanitaaria valdkonnas, mille

\footnotetext{
${ }^{1}$ Neist saab kõige parema ülevaate, kui lugeda Matthew K. Goldi koostatud antoloogiaid: Gold 2012; Gold, Klein 2016, 2019. Hea sissejuhatuse pakub samuti Melissa Terrase, Julianne Nyhani ja Edward Vanhoutte’i koostatud lugemik „Digihumanitaaria defineerimine” (2013).
} 
tähendusväli pole potentsiaalselt kitsam. Kui vaadata lähemalt digihumanitaarset uurimistööd, siis torkab kiiresti silma, et see ei kata kaugeltki kõiki humanitaaria valdkondi võrdsel määral. Suurem osa digihumanitaariast tegeleb ennekõike tekstiandmetega, filoloogilise uurimistööga selle sõna kõige avaramas tähenduses. Kuid pigem vaeslapse osas on need humanitaaria valdkonnad, kus töötatakse peamiselt pildiliste, esemeliste, ruumiliste, heliliste ja multimodaalsete andmetega. Digitaalset kunsti- ja muusikateadust viljeldakse oluliselt vähem kui digitaalset keele- ja kirjandusteadust, rääkimata näiteks digitaalsest filosoofiast. Seega on digihumanitaaria mõneti eksitav nimetus, sest lubab rohkem, kui tegelikult pakub.

Kuid digihumanitaaria on ühtlasi liiga kitsendav nimetus, et sobida digitaalselt rikastatud uurimistöö kirjeldamiseks. See aitab elus hoida vana, peamiselt XIX sajandil välja kujunenud vastandust kultuuri- ja loodusteaduste, vaimu- ja reaalteaduste vahel, mida digitehnoloogia võiks aidata ületada, mitte kinnistada. Selmet piirata ennast üksnes humaniora'ga, võiks tänapäeva kultuuriuurija püüelda pigem valdkonnaülese koostöö poole sotsiaalteaduste, arvutiteaduse, võrgustikuteaduse, komplekssüsteemide teooria, masinõppe ja tehisintellekti uuringute ning teiste n-ö mittehumanitaarsete erialadega. Niisiis peaks eesmärk olema leida uue, siiani väljakujunemises oleva valdkonna kohta nimetusi, mis ei põlista üle-eelmise sajandi distsipliinipiire, vaid soosivad nende ületamist.

Niisamuti on problemaatiline eesliite digi- kasutamine. See tekitab paratamatult vastanduse „analoog-” või traditsioonilise humanitaariaga, mis ei ole kuidagi põhjendatud. Esiteks on rangelt võttes iga humanitaarteadlane „digihumanitaar” selles mõttes, et ta kasutab oma uurimistöös digitehnoloogilisi töövahendeid (olgu selleks või tekstitöötlusprogrammid ja uurimisandmed kõvakettal), küsimus on vaid digivahendite kasutamise määras. Teiseks loob see pettekujutelma, nagu tegeleks digihumanitaaria sootuks teise ainesega kui traditsiooniline humanitaaria, kuigi allikate digiteerimine ei muuda tingimata nende sisu ega olemust. Ainult väike osa digihumanitaariast keskendub n-ö digitaalselt sündinud teabele, valdavalt töötatakse siiski digiteeritud materjalidega, mille kasutamine eeldab üldjuhul samasuguseid kutseoskusi nagu „analooghumanitaarias”. Muidugi on digihumanitaaria egiidi all toodud humanitaarteaduslikku uurimistöösse mitmeid uusi meetodeid, ent metodoloogiline uuenemine iseloomustab humanitaariat algusest peale ja see ei eelda tingimata valdkonna ümbernimetamist. Digi-eesliite rõhutamine võib tekitada olukorra, kus digihumanitaare käsitatakse klassikalise humanitaarse teadustöö tugiisikutena, tehnilise abipersonalina, kes aitavad arvutada, visualiseerida või mudeldada seda tööd, mida teevad n-ö pärishumanitaarid. Praeguses institutsionaalses töökorralduses on näha, et paljud n-ö digihumanitaaria spetsialistid leiavad tööd ennekõike raamatukogudes ja arhiivides, mitte ülikoolides, kus vastavaid töökohti tuleb endiselt tikutulega otsida.

Digihumanitaaria kritiseerimisel on juba auväärne traditsioon, seda nii valdkonna sees kui ka seda enam väljaspool. See on kindlasti põhjuseks, miks nii mõnedki autorid on nimetuse ebamäärasust püüdnud välja mängida selle tugevusena. Nii nimetab näiteks Matthew Kirschenbaum (2012) digihumanitaariat „taktikaliseks terminiks", mis aitab saavutada praktilisi eesmärke, näiteks hankida rahastust või 
luua ametikohti. Sageli räg̈gitakse digihumanitaariast kui katusterminist või kui nn suurest telgist (ingl big tent), mille alla mahub palju eriilmelisi tegevusi (nt Svensson 2012; Weingart, Eichmann-Kalwara 2017). James Smithies (2017: 2) viitab aga digihumanitaariale kui „ujuvale tähistajale”. Steven Jones (2014: 5) resümeerib asjakohaselt: „Endiselt ei ole selge, kas digihumanitaariat tuleks pidada valdkonnaks või (inter)distsipliiniks või lihtsalt praegu mugavusest kasutatavaks nimetuseks selle kohta, mida kõik humanitaarid üpris varsti tegema hakkavad.” Teises mõjukas sedastuses kirjutasid Todd Pressner ja Jeffrey Schnapp oma „Digihumanitaaria manifestis 2.0” (2009): „Digihumanitaaria ei ole ühtne valdkond, vaid rida koonduvaid praktikaid, mis uurivad üht universumit."

Üha enam kohtab katseid täpsustada digihumanitaaria nimetust mõne täiendi toel. Nii on näiteks mõned autorid, kes soovivad näha digihumanitaarias ennekõike revolutsioonilist potentsiaali, mis mängiks ümber senise humanitaarteaduste korralduse, kutsunud üles edendama „transformatiivset digihumanitaariat” (transformative digital humanities, vt Balkun, Deyrup 2020). Teised on soovitanud lõimida digihumanitaariat kriitilise teooriaga ja pakkunud välja „kriitilise digihumanitaaria” (critical digital humanities) nimetuse (Berry, Fagerjord 2017: 136-150; vt ka Berry 2014).

Kuid need katsed mängida digihumanitaaria ebamäärasus välja selle taktikalise tugevusena või piirata seda uute täiendite lisamisega ei tundu perspektiivikad. Seega teeme ettepaneku käsitada digihumanitaariat selle menule ja populaarsusele vaatamata üleminekuaja nimetusena, ajutise võitlusloosungina, mis on aidanud valdkonnale tähelepanu tõmmata ja huvilisi mobiliseerida, mille raames on tehtud olulist metodoloogilist arendustööd, ent mis praeguses arenguetapis vajab väljavahetamist konkreetsemate ja vanadest vastandustest vabade nimetuste vastu.

Me näeme selget vajadust vabaneda mitmest eristusest, mis on digihumanitaaria projekti sisse kirjutatud. Esiteks tuleb ületada eristus idiograafiliste nähtuste kvalitatiivse ja nomoteetiliste nähtuste kvantitatiivse analüüsi vahel. Teiseks tuleb ületada üksiku ja üldise, osa ja terviku uurimise dihhotoomia. Kolmandaks tuleb ületada digitaalse ja analoogse vastandamine, sest leidub mitmeid asjakohaseid arvutuslikke ja uurimuslikke ülesandeid, mis eeldavad pigem mittedigitaalseid lahendusi. Ja neljandaks tuleb püüda väljuda humanitaarteaduste klassikalistest piiridest ning arendada dialoogi näiteks komplekssüsteemide teooria, masinõppe, süsteemibioloogia, evolutsioonilise majandusteooria ja paljude teiste uurimissuundadega. Pakume välja, et kultuuriandmete analüüs võiks olla üks neid uusi uurimisvaldkondi, mida arendada teispool digihumanitaariat ja mis võiks aidata sõnastatud eristusi ületada. Põhjuseid selleks üritame allpool esitada, aga sissejuhatuseks rõhutagem, et mõiste kultuur tähendus on küll samamoodi lai nagu mõistel humanitaaria, kuid see ei viita mitte institutsionaliseerunud akadeemilisele valdkonnale, vaid uurimisobjektile: uuritakse kultuuri tähendussüsteeme ja praktikaid, samuti kultuuri erinevaid materiaalseid ja mittemateriaalseid esinemisvorme ning nende kõigi muutumist ajas. Mõiste andmed rõhutab aga asjaolu, et pärast digitaalset kodeerimist muutuvad kultuurisisu ja -praktikad andmeteks, mida saab uurimisülesanneteks eri viisil ümber organiseerida, nii et see rikastab märkimisväärselt uurimiseks kasutatavat 
metoodikat (ennekõike võimaldades teistest distsipliinidest meetodeid laenata). Teisalt tõstatab andmete mõiste selgemalt ka kriitilise refleksiooni vajaduse uurimistöös, sest andmed on pahatihti problemaatilised või eksitavad. Kombinatoorne mõiste kultuuriandmed viitab omakorda sellele, et kultuuri saab uurida, ristates eri andmekogusid, mis on kogutud eri viisil ja võivad viidata väga erinevatele modaalsustele, nii kultuuri artefaktidele, sisule kui ka praktikatele. Selline analüüs võimaldab keskenduda kultuuri komplekssete sisesuhete uurimisele, mille selgitamise juurde järgmiseks pöördume.

\section{Kultuuri komplekssuse mõtestamine}

Teel uue lähenemise poole, mida nimetame kultuuriandmete analüüsiks, toome esimesena esile komplekssuse mõiste, mida võib pidada ühenduslüliks kultuuri uurimise eri lähenemiste - see tähendab, kultuurinähtuste ja -protsesside nn nomoteetiliste ja idiograafiliste vaatenurkade - vahel. Ajalooliselt on humanitaarteadusi pärssinud eeldus, et need peavad keskenduma üksiknähtustele, sageli vastandudes loodusteadustele, mis vaatlevad väidetavalt ainult üldisi nähtusi. Tavalugejale või asjatundjale võib see tunduda liialdatud vastandus, ent nagu iga valdkonnaüleste huvidega teadlane võib kinnitada, on selle taga karm tegelikkus. See tegelikkus, mida tuntakse „kahe kultuurina” (Snow 2017 [1961]), ei tähenda, et vastandus oleks sisuline - seda ta ei ole -, vaid et seda kasutatakse relvana eelretsenseerimisel, värbamiskomisjonides ja rahastamisotsustes.

Niisiis on arukas üle korrata, kust pärineb kahe väidetavalt vastandliku teaduskultuuri argument. Humanitaaria, seega ka digihumanitaaria ja loodusteaduste ideoloogiline lahutamine põhineb XIX sajandi filosoofial, täpsemalt Wilhelm Dilthey töödel. Temalt pärineb vaimuteaduste (sks Geisteswissenschaften) ja loodusteaduste (sks Naturwissenschaften) vastandus (Dilthey 1959 [1883], 1997). Tuleb küll täpsustada, et Dilthey jaoks ei olnud see vastandus nii absoluutne nagu paljudele tema järgijatele. Dilthey käsituses erinevad loodus- ja vaimuteadused teineteisest esmajoones oma uurimisobjektide konstitueerimise poolest: kui vaimuteadusliku teadmise põhjendus tuleb leida sisemise kogemuse analüüsist, siis loodusteaduste pärusmaaks jääb välise kogemuse eritlus. Algusest peale on tähelepanuväärne, et see vaimumaailma ja füüsilise maailma lahutamine mitte ainult ei toimunud enne suuri arenguid kõigis teadustes, vaid oli juba XIX sajandil vastuolus näiteks Goethe esitatud seisukohaga, mis on toodud ära ajakirja Nature esimeses numbris 1869. aastal: „Ka kõige ebaloomulikum on siiski looduse loomulik osa" (Huxley 1869). Samal ajal kui ajakiri Nature hakkas iroonilisel kombel edaspidi kultuuriuurimusi valdavalt ignoreerima, kinnistas teine saksa teadlane Wilhelm Windelband veelgi kindlamalt humanitaarja loodusteaduste eraldamise, mõeldes välja kaks terminit, millega iseloomustada nende väidetavalt ületamatut erinevust (Windelband 1993 [1894]). Windelband väitis, et loodusteadused on peamiselt nomoteetilised, otsetõlkes „seadust andvad” teadused, mis püüavad mustrite põhjal tuvastada seaduspärasusi. Ilmselge näide oleks see, et füüsilised esemed „lihtsalt” järgivad liikumise seadusi, mille sõnastas 
Isaac Newton. Seevastu vaimuteadused, nagu Windelband väitis, on idiograafilised ja keskenduvad üksikjuhtumitele. Selle vaate kohaselt on ajaloolised sündmused alati kordumatud, umbes nagu see mitte kunagi täielikult korduv olukord, milles meie seda artiklit kirjutame või teie seda loete.

Kui võtta omaks selline vaatenurk, võib kultuurinähtuste kvantifitseerimine tunduda keelualale tungimisena, sest selle ainus eesmärk saab olla nomoteetiliste kultuuriseaduste sõnastamine. Digikultuuri laiema kontseptualiseerimise kontekstis on selle näiteks olnud Friedrich Kittleri kriitika Niklas Luhmanni süsteemiteoreetilise sotsioloogia aadressil. Kittler töötas välja uue lähenemise (mida tuntakse meediaarheoloogia nime all), et uurida kultuuri muutumist ajaloos vastavalt sellele, millised materjalid ja tehnilised meediaressursid olid parasjagu kättesaadavad. Nii jõudis ta radikaalse historitsismini, mille eesmärk oli lammutada näiteks selliste mõistete nagu meedia ning teiste kommunikatsioonivoogusid korraldavate ja tähendusi loovate kultuuriinstitutsioonide universaalsus. Sellest lähtudes oli ta vastu ka laiematele seadusesarnastele ühiskondliku või kultuurilise evolutsiooni teooriatele, kaasa arvatud Luhmanni omadele (vt Kittler 1994; Winthrop-Young 2000: 411).

Ometi on olnud ka vastuliikumisi ja alternatiivseid ettepanekuid, millest kõige silmapaistvama esitas Raymond Williams, kui ta sõnastas vajaduse kultuuriuuringute (ingl cultural studies) kui uue kultuurianalüüsi meetodi järele. Williams järgis Birminghami nüüdisaja kultuuriuuringute keskuse (Birmingham Centre for Contemporary Cultural Studies) eeskuju - sealgi keskenduti algselt saksa kultuuriteaduste (Kulturwissenschaften) importimisele ingliskeelsesse akadeemilisse maailma (vt Shuttleworth 1966). 1974. aastal pidas Williams ettekande, kus pakkus välja uue lähenemise, mida ta nimetas kõigepealt kultuuriteaduseks ja mille hiljem muutis kultuuriuuringuteks (mis tema järgi on korrektne ingliskeelne vaste saksa Kulturwissenschaft'ile; Williams 1974). Selles ettekandes lähtus ta Dilthey, Weberi ja Marxi saksa intellektuaalsest pärandist, ent soovis minna kaugemale: määratleda „erinevate praktikate vahelised suhted” XX sajandi teise poole kultuuriteaduse „keskse probleemina” (vt Hartley 2009). Kuigi sellest hoolimata keskendusid kultuuriuuringud edaspidi siiski kultuuri mikrokontekstidele, on nüüd seoses kultuuriandmete analüüsi esilekerkimisega saanud võimalikuks teha algust kultuuris esinevate suhete süstemaatilise analüüsiga ka makrotasandil.

Tuleb rõhutada, et humanitaarteadustest ei ole kunagi puudunud n-ö seadusesarnased üldistused. Tõepoolest, humanitaarteaduste õpikuteadmised ja haridus on täis vaistlikke üldistusi, tüüpe ja kategooriaid, mis eeldavad vähemalt vaikimisi mingit näidetel põhinevat keskmist koondit. Selline üldistus on näiteks gooti kaar 20-eurosel rahatähel. Teisisõnu, võime ette kujutada keskmist gooti katedraali, kuigi sellist keskmist olemas ei ole. Esimene konkreetne katedraal, mis pähe tuleb, on tõenäoliselt silmapaistev, mitte keskmine näide. Musternäidet ennast ümbritseb tavaliselt suurem hulk vähem tüüpilisi näiteid. Sellegipoolest on üldistus loogiline, sest nii on võimalik käsitleda eripära üksikute näidete lõikes. Üksikute konkreetsete tähelepanekute ja üldistuste vaheliste suhete uurimine ja sedastamine on humanitaarteaduste lahutamatu osa, mida tuntakse hermeneutilise ringi nime all - järjekordne Diltheyga seonduv saksa filosoofia mõiste (vt nt Bod 2014: 333-334). 
Teisisõnu on selge, et nii üksikjuhtumite uurimine kui ka üldistamine on kultuurinähtuste mõistmiseks hädavajalikud tegevused. Pigem on asi selles, et kultuurinähtused on komplekssed ega järgi tingimata „lihtsaid” kvantitatiivseid seadusi, millel on „lihtsad” sisulised keskmised. See on oluline põhimõte ja tuleks pikemalt lahti seletada. Siinsel juhul ei tähenda kompleksne pelgalt keerulist, mis on selle sõna kõige levinum tähendus (Zinoviev 2016). Sõna kompleksne, mida me siin kasutame kompleksteaduse mõistes (Mitchell 2009; Complexity Explained; Engelbrecht, Kitt 2020), on mõnes mõttes vastuolus üldlevinud arusaamaga komplitseeritusest. Üksik ajaloosündmus, nagu ka konkreetne maal või visualiseering bioloogiaalases teadustöös võivad olla komplitseeritud, ning meie mõistmise suurendamiseks on vaja teostada nende hoolas vaatlus ja diferentseeritud kvalitatiivne uurimistöö. Teisalt võib suurem hulk näiliselt lihtsaid ja eraldiseisvaid kultuurilisi suhteid anda kokku kompleksse mustri, kus esineb teatavaid korrapärasid, kuid samal ajal ka spetsiifilisi variatsioone. Komplikatsiooni mõistega täiesti lõpuni minnes võime eksida spetsiifiliste, erisuguste detailide massi, samas kui komplekssus võib kujuneda mõnest lihtsast protsessist. Kujundid, mille moodustab kuldnokaparv, kus kõik linnud on ühesugused ja järgivad mingit hulka suhteliselt lihtsaid reegleid, on üks sellise or g a niseeritud komplekssuse näide (Weaver 1948). Teine on linnastruktuur ja -dünaamika, mis tekib linnaelanike kohalike tegevuste tulemusena (Jacobs 1961; Barthelemy 2019). Sarnaseid nähtusi, kus ühe konkreetse osise lokaalsest tegevusest kujuneb organiseeritud komplekssus, võib leida kõikjal maailmas: tuumafüüsikast arenes molekulaarkeemia, mis viis omakorda rakubioloogia ja organismideni, seejärel teadvuse ja sotsiaalse suhtluseni, ning lõpuks tekkisid materiaalsed ja mittemateriaalsed kultuuritooted (Anderson 1972; Riedl 2000).

Igal tasandil, kus komplekssus tekib kohalikust tegevusest, saab tervik mitte üksnes suurem, vaid ka teistsugune ehk "rohkem on erinev" (ingl more is different), nagu Paul Anderson 1972. aastal löövalt sedastas. Selle tagajärjel tekib üllatav võimalus kvalitatiivseks uurimistööks: tõenäoliselt on humanitaarteadustes kvantifitseerimise tulemus mitte lihtsalt kvantitatiivsed seadused, vaid kvaliteedi uudsed vormid. Kohalike spetsiifikate kooskõlast kerkivad esile uued huvitavad klastrid, ka esmapilgul segadusse ajavad mustrid ning erinevate statistiliste mudelite võrdlusvõimalused koos ilmnevate tähenduslike eranditega. Meso- ja makrotasandil leiame äratuntavaid kvalitatiivseid nähtusi, mis pole täielikult ei korrapärased ega ka juhuslikud, meenutades linnatänavate mustreid või maastike topograafiaid, mis saavad nähtavaks lennukõrguselt (Lee jt 2017; Mandelbrot 1982). Suured kogused lihtsaid suhteid, nagu saja tuhande teadaoleva üksikisiku sünni- ja surmakoha omavahel ühendamine, võivad viia kultuuriajaloo metanarratiivi ja kaua otsitud n-ö keskmise kestusega mustrite ilmnemiseni mesotasandil, samal ajal kui makrotasandil saavad ilmsiks demograafilised „rändeseadused” (Schich jt 2014; Ravenstein 1885; Hexter 1972). Süstemaatiline nihe, mis ulatub kaugemale üksikisiku loomulikust kognitiivsest piirist, tuleb esile mitme suure andmestiku võrdleval analüüsil, samas kui kõik eelnimetatu jääb kitsamalt kohalikele eripäradele keskendudes varjatuks.

Samal ajal - ja see on oluline - nihkub fookus sisult funktsioonile, esemetelt suhetele, struktuurilt dünaamikale ning sünteesilt analüüsile (Schich 2019; Cassirer 
2010 [1910]. Kuigi võib väita, et humanitaarteadused on alati olnud huvitatud kontekstidest ja konkreetsetest sündmustest, ei saa eitada, et mitmed põhidistsipliinid alates kunstiajaloost ja kirjandusest, lõpetades meediauuringutega määratlevad end endiselt ennekõike sisu kaudu: uuritakse kunstiteoseid, tekste, filme või muid meediume. Sealjuures on aga praeguseks tehtud suuri edusamme nende omavaheliste interaktsioonide mõistmisel, ning kompleksvõrgustike teadus on üha levinum hulgas valdkondades, kus komplekssus kujuneb kohalikust tegevusest - alates füüsikast ja lõpetades kultuuriga (Barabási 2016; Schich 2016; Schich jt 2016; Ahnert jt 2021).

Kultuurisuhetest tärkava komplekssuse kvantifitseerimisel ei ole ohtu, et tavapärane hermeneutiline teadustöö humanitaarteaduses asendataks lühinägelike mehhanistlike või positivistlike kultuurimudelitega. Tekkiva komplekssuse kvantifitseerimine võib hoopis pakkuda võimalust täpsustada kollektiivses hermeneutilises ringis kujunevaid arusaamu, kui humanitaarne loogika ja intuitsioon kohtuvad kvantitatiivsete tõenditega, mis on omakorda mõeldamatud ilma kumulatiivsete tõendite hoolika kvalitatiivse kaardistamiseta.

\section{Üksik ja üldine moodustavad semiosfäcari}

Üksiku ja üldise, makro- ja mikrotasandi komplekssuste mõtestatud seostamiseks on juba olemas üks, meil Eestis käepärane lähenemine - see on kultuurisemiootika. Pakume, et uue andmeanalüütilise põhjaga kultuuriteadusliku uurimisprogrammi arendamiseks võib just Eesti olla sobilik ja ainulaadne paik, kuna oleme siin kujunenud parimateks ekspertideks Juri Lotmani semiosfääri teooria vallas. Oleme seda ka edasi arendanud ning vorminud selle läbimõeldud raamistikuks, mis lubab analüüsida kompleksseid ja dünaamiliselt arenevaid kultuuriprotsesse. Pakume, et Lotmani hilise loomeperioodi teooria kui süsteemiteoreetiline ja holistlik lähenemine kultuuridünaamikale on hea alus nüüdisaegsete digitaalselt vahendatud või võimaldatud kultuuriprotsesside uurimiseks (vt Hartley jt 2021a).

Kultuurisemiootika ja kultuuriandmete analüüsi hea klapp ei ole juhuslik, tugines ju Lotman oma teooria väljatöötamisel suurel määral küberneetikateooriatele (ennekõike Norbert Wieneri ja Ross Ashby töödele) ja mitmesugustele teistele lähenemistele (sh Ilya Prigogine’i (Prigogine, Stengers 2018 [1984]) töödele dissipatiivsetest struktuuridest ja iseorganiseerumisest), mida tänapäeval peetakse nii süsteemikui ka posthumanistlike teooriate eelkäijateks. Tõstkem siinkohal esile ka Jakob von Uexkülli töö $(1909,2012)$ mõju kultuurisemiootika edasiarendustele pärast Lotmanit (Kull, Lotman 1995; Kull 1998). Digikultuuri süsteemse uurimise kontekstis on oluline nimetada, et ka Ludwig von Bertalanffyd inspireeris üldise süsteemiteooria (1951) väljatöötamisel just Uexkülli teadustöö.

Nii eelnimetatuid kui ka kultuurisemiootika nüüdisaegseid arendajaid on mõjutanud ennekõike Uexkülli omailma (sks Umwelt) mõiste. Eluslooduse eri liikide, aga ka eri inimeste omailmad võivad olla väga erinevad, sõltuvalt nende tajukanalite (meelte) spetsiifilistest lubavustest. Omailmadevahelistes tõlgetes tekib esmane 
jagatud tähendussüsteem. Mida rohkem on selliseid tõlkeid ehk omavahel suhtlevaid üksusi, seda rohkem on ka eraldiseisvaid tähendussüsteeme, mis kõik kokku moodustavad nn semiosfääri - jagatud, ühiselt toodetud tähenduste süsteemi. Seejuures tuleb aga rõhutada, et nii esmalt Uexkülli kui hiljem ka Lotmani jaoks algas igasugune suurema süsteemi, sh kultuuri kujunemine selle allsüsteemide autokommunikatsioonist (Kull, Lotman 2012; Torop 2008). Lotmani jaoks tähendab autokommunikatsioon süsteemi võimet iseendast rääkida, end oma keskkonnas eristada ja defineerida ning seeläbi kommunikatiivselt luua. See on ka võime toota enesekohaseid tekste, seejuures keskkonnast tähenduslikuna näivat süsteemi sisse tõlkida, seda oma seniste koodidega jooksvalt lõimida ja nii omasüsteemi uuendada. Arvestades, et eri süsteemid - näiteks eri kunstižanrid, poliitilised ideoloogiad või idufirmade kogukonnad - moodustavad üksteisele keskkonna, tähendab kultuuri areng protsesse, kus nood süsteemid üksteist tõlgivad ja nõnda omasüsteeme muutuvas keskkonnas taasloovad, ümbritseva keskkonnaga kohandavad. Selliseid süsteeme võib olla väga väikseid (nt paari artisti poolt loodud ja lühiajaliselt kestev muusikažanr), keskmises suuruses (nt Eesti rahvuskultuur) ja väga suuri (kogu inimkultuur või nt YouTube'is viljeldav, miljardite inimeste koosloomes sündiv audiovisuaalkultuur).

Seejuures on aga kultuurisemiootika keskne idee, et kõik tasandid tingivad üksteist. Näiteks ei saaks üksik uus muusikažanr sündida ilma selleta, et kogu ülejäänud kultuuriruum enne eksisteeriks - see on tähenduslik, eriline ja „uus” vaid kogu muu kultuuri kontekstis, tõukub kõigest eelnevast kausaalselt. Kui aga uus kultuurivorm või rühmitus ja seda kandev diskursus sünnivad, nihutavad need omakorda paigast kogu olemasoleva kultuurisüsteemi - ka kõik muud kultuuri allsüsteemid peavad kas otsesemalt või kaudsemalt sellega arvestama, sellega kohanema ja nii muutub lõpuks kogu üleilmne semiosfäär. Eelnevaga seondub veel üks kultuurisemiootika juhtpõhimõte: eri tasandite süsteemid on n-ö isomorfsed, nad on teatud mõttes sarnase struktuuriga, analüüsides üht, saab teha järeldusi teise kohta. Just sellest põhimõttest lähtudes on võimalik näiteks üksikute materiaalsete fragmentide põhjal teha olulisi järeldusi möödanikukultuuride struktuursete seatuste kohta.

Siit johtub, et semiosfääri teooria on ülal kirjeldatud nomoteetiliste ja idiograafiliste lähenemiste üks võimalik kompromiss või ühendaja. Sest selle eeldus on, et üks tingib teise, üht uurides saab teha teise kohta järeldusi, ning mis veelgi olulisem: uurides autokommunikatiivset või iseorganiseerumise dünaamikat kultuuri eri allsüsteemides, nii väga väikestes kui ka väga suurtes, samuti nendevahelisi suhteid või tõlkeid, saab süsteemselt uurida põhjuslikke seoseid kultuuri eri allsüsteemide arengute vahel läbi aegade. Eespool selgitasime, miks on komplekssus oluline mõiste eri tasandite kultuurinähtuste mõistmisel ja kontekstualiseerimisel ning et komplekssust võib vaadelda nii kultuuri mikrotasandil, spetsiifilisi nähtusi uurides kui ka meso- või makrotasandil, kus ilmnevad mikrotasandi protsesside interaktsioonid. Kultuurisemiootilises vaates sünnibki aga komplekssus eri tasandi süsteemide autokommunikatiivsest või modelleerivast tegevusest. Väikesed süsteemid on hõlmatud korraga mitmesse suuremasse kultuurisüsteemi, mis on väiksemate suhtes nomo- 
teetilised, kuid mis koosmõjus toovad nende keskkonda/konteksti komplekssust. Samas toodab väikeste süsteemide iseorganiseerumine, autokommunikatsioon ja modelleeriv tegevus uut komplekssust, mis võib viia suured süsteemid muutusteni. Sellist komplekssuse esilekerkimist eri tasandite koosmõjul on võimalik uute kultuuriandmete analüüsi meetoditega uurida. Seni oli selline kultuurisemiootika ideestikust lähtuv uurimisprogramm võimalik vaid hüpoteetiliselt või väikeses mahus, nüüd on sellest suurte andmekorpuste ning kultuuriandmete analüüsi areneva meetodiarsenali toel reaalsus saamas.

Järgnevalt tõstame esile ühe kultuurisemiootilise mõiste, mida saaks ja tuleks erinevatel viisidel kultuuriandmete analüüsis operatsionaliseerida ehk kasulikult rakendada. See ei lähtu küll otseselt kultuurisemiootikast, vaid nn kultuuriteadusest (ingl cultural science) - Austraalia õpetlase John Hartley ja tema kolleegide rajatud uurimissuunast, mis tugineb kultuurisemiootikale, aga ka kultuuriuuringutele, komplekssusteadusele ja evolutsioonilisele majandusteadusele (vt Hartley, Potts 2014; Hartley 2020). See mõiste on deem (ingl deme) ja see viitab autokommunikatiivselt toimivale inimrühmale, keda ühendavad peale ühise enesekohase diskursuse ja seda kandvate tekstide ka ühised meediakanalid, -vormid ja kommunikatsioonivahendid. Näitena tänapäevast saab siin tuua ühised Telegrami või Facebooki grupid või ehk jälle tihedalt lõimitud Twitteri võrgustikud. Vanema aja näited oleksid enne trükipressi ühist kirjavara loonud ja lugenud Euroopa vaimulikud või ka XX sajandi teise poole Eesti kineastid/dokumentalistid, keda ühendasid meedium, žanrid ja tasapisi ajas muutuvad ideed ja diskursused, mida filmides ka väljendati. Twitteripõhiseid deeme on tänapäeval võrgustikuanalüüsi meetoditega lihtne uurida, kuid kasutades näiteks Eesti Filmi Andmebaasi metaandmete korpust, saab sama edukalt analüüsida ka Eesti kineastide ajaloolisi võrgustikke ja deeme (vt Ibrus, Ojamaa 2020).

Peilides aga näiteks Eesti subkultuursete muusikakogukondade Facebooki gruppe ja sealseid autokommunikatiivseid praktikaid ehk enesekohast tekstiloomet, saab uurida, kuidas neis subkultuurides identiteeti luuakse, kuidas end keskkonnast eristatakse ja eriti kuidas seda tehakse pikkade perioodide lõikes (sellega tegeleb praegu oma doktoritöös Madis Järvekülg). Otsides eri gruppide vahelisi linke või neid sidestavaid inimesi, uurides ka neis gruppides aset leidva autokommunikatsiooni sarnasusi ja erinevusi, saab edasi uurida, kuidas on erinevad subkultuurid seotud, kuidas info nende vahel liigub, kuidas nad üksteist tõlgivad. Lähtudes nii Lotmani kultuurisemiootikast kui ka Hartley ja Jason Pottsi kultuuriteadusest, on sama oluline ka deemide eristumispraktikate, sh konfliktide uurimine. Sest eristumises ja konfliktis väljenduvad erinevate ajastute olulised alternatiivid, samuti plahvatuslikud arengud, mille tulemuseks võivad olla uued, teistel alustel toimivad dialoogid või ühendsüsteemid. Näiteks on Hartley, Ibrus ja Maarja Ojamaa (2021b) näidanud konflikti üleilmsete kliimaliikumiste ja vandenõuteooriate internetikogukondade vahel, mis aga samas on paradoksaalselt kujunenud ka dialoogiliseks - need süsteemid on koevolutsioonilised. Eri tasanditel aset leidvate dialoogide, konfliktide, tõlgete ja autokommunikatsiooni praktikaid andmeanalüüsi meetoditega uurides hakkab lõpuks kokku tulema laiema kultuuridünaamika pilt. 
Tallinna Ülikoolis arendame parasjagu koos ERR-i ja Postimees Grupiga, samuti Balti Meediamonitooringuga uurimisprojekte, milles püüame eelkirjeldatud mõisteid ja neist lähtuvaid küsimusi rakendada Eesti ajakirjanduslikele andmebaasidele ja nende aastakümneid katvatele tekstikogudele. Metaandmete andmebaasidest saab kätte tekstide/saadete loojad, masinõppealgoritmide ja muude meetodite abil saab neist tuvastada rääkijad ja tegutsejad ning teised olemid, samuti modelleerida tekstide teemasid. Kõiki neid elemente saab ühendada võrgustikeks ja uurida nende muutumist ajas. Saab uurida, kuidas moodustasid ühiskonnas aktiivsed inimesed erinevaid temaatilisi või diskursiivseid deeme, kuidas nad infot/diskursusi/keelt vahetasid ja üksteise vastasmõjus, üksteist tõlkides arenesid.

Kui naasta diskussiooni juurde nomoteetilise ja idiograafilise lähenemise vastuoludest ning kultuurisemiootikast kui kompromissist, siis mainitud uurimistöös soovime näidata, kuidas on laiem kultuuridünaamika tinginud üksikute tekstide (näiteks konkreetsete telesaadete) esilekerkimist ning kuidas need kui ülalkirjeldatud lihtsad mikrotasandi nähtused on omakorda tinginud uute komplekssemate deemide organiseerumist ja edasist muutust terviksüsteemis.

Tuleb aga vaadata ka kaugemale: kas seda tüüpi uurimisprogrammi saaks arendada rakenduslikuks, tulevikku vaatavaks, mitmesuguseid tänapäevaseid väljakutseid (valeinfo levik, kiirelt eskaleeruvad veebikonfliktid jms) käsitlevaks uurimistööks? Kas meie pakutaval uurimisprogrammil saaks olla ka kultuuri- ja meediapoliitiline mõõde? Mõtelgem tagasi meteoroloogia arengule: praeguse täpsuse saavutamiseks kulus ligi kaks sajandit. Alguses peeti seda lootusetuks narruseks, nüüd on see aga üks arenenumaid valdkondi, mis suurte andmemahtude kiirkäitlemise edukust tõendab, pakkudes seejuures kõigile kättesaadavat avalikku hüvet. Kui alguses, XIX sajandi keskpaigas, pilgati esimesi eksperimenteerijaid, siis tänapäeval on tegu maailmamajanduse ja ühiskondade igapäevaelu planeerimisel hädavajaliku teabega. Kliimakriisi arenedes valdkonna tähtsus aina kasvab. Kas ka kultuuriandmete analüüs saaks areneda prognoosivaks (st mitte kindlalt ennustavaks, aga kalkuleerivalt ettevaatavaks) teaduseks?

Selle potentsiaali avamisele suunatud uurimistöö avalik-õiguslikes ülikoolides on seda olulisem, et erasektoris on see käimas nii ehk naa - asjaolu, mis sai selgeks hiljemalt Cambridge Analytica skandaaliga (Isaak, Hanna 2018). Kuid viimane oli siiski suhteliselt vähese mõju ja tegevusulatusega. Enamiku andmeid meie sotsiaalse elu, sidemete ja huvide, kultuurilise tähendusloome kohta koguvad ja salvestavad ülemaailmsed suurplatvormid. Nick Couldry ja Ulises Mejias (2019) nimetavad seda andmekolonialismiks. Kui kolonialismi esimene laine tähendas, et lääneriigid annekteerisid tooraine hankimiseks territooriume mujalt, siis uue laine kolonialism seisneb selles, et suurplatvormid ja nendega seotud ,andmestamistööstused” mudeldavad ja seeläbi koloniseerivad inimeste elusid, nii erasfäri kui ka sotsiaalset elu, et neist isetahtsi väärtusi ekstraheerida. Koos $5 \mathrm{G}$ ja asjade interneti levikuga võib selline elude kaubastamine andmestamise kaudu kujuneda üsna laialdaseks.

Kultuurisemiootika põhise kultuuriandmete analüüsi loomulik eesmärk peaks olema eelkirjeldatud protsesse eirata ja väärata. Siin tuleb silmas pidada, et kultuurisemiootika järgi lisab igasugune mudeldamine, ka teaduslik, laiemasse kultuuri- 
ruumi mudeleid juurde. Nagu Peeter Torop (2015) on näidanud, iseloomustab aga kultuurisemiootikat teadlikkus oma tegevuse tulemustest. See aga ei tähenda, et tegevustest peab hoiduma, vaid tuleb panustada kasulike mudelitega. Kui kultuurisemiootika teesiks on olnud, et kultuuri arengu ja hea talitlusvõime eelduseks on selle sisemine mitmekesisus, siis peavad analüütilised tegevused panustama mudelitega, mis seda mitmekesisust tõstavad, avavad nii uusi reaalsusi kui ka osutavad kultuuri allsüsteemide rikkusele.

Semiosfäärilise modelleerimise toel saab näidata, kuidas teadmised ja väärtused kultuuris sünnivad ja levivad paljude inimeste tegevuse toel. Selline modelleerimine on iseenesest valgustav kultuuri toimemehhanismide osas, vähendades potentsiaalselt ebausku, usaldamatust ning gruppidevahelisi hirme. Kuid ühtlasi aitab see ennustada konfliktikoldeid ja turbulentseid perioode. Kui aktsepteerime asjaolu, et inimkultuur ehk semiosfäär mõjutab ja vormib antropotseeni ajastul muid süsteeme (biosfäär, geosfäär, atmosfäär), siis tuleb semiosfääri planetaarset toimimist võimalikult hästi mõista, et hinnata selle riske elukeskkonnale. Nii peaks globaalsete kultuuriliste protsesside prognoosimise eesmärk olema ennekõike a valiku väärtuse (Benington, Moore 2011; Mazzucato 2018) loomine - st kõigile osapooltele kättesaadavate teadmiste tootmine ja jagamine. See tähendab ennekõike nn hea valitsemistava huvides prognoosimist.

Kogu eelnevat potentsiaali rõhutades tuleb tunnistada, et sellisel üleilmse kultuuridünaamika modelleerimisel on ka oma olulised kitsaskohad. Meenutagem siinkohal Jorge Luis Borgese lühinovelli „Täpsusest teaduses” („Del rigor en la ciencia”), kus tundmatu impeeriumi kartograafid koostasid üksikasjaliku 1:1 kaardi kogu oma riigi kohta. Kuid selle elanikud leidsid eelduspäraselt, et see on kasutu, ja kaart hävitati. Et 5G mobiilside, asjade internet ja liitreaalsuse rakendused on peatselt tegelikkuseks saamas, mängitakse taas ideedega kogu füüsilise ruumi nn peegelmaailma või digitaalse kaksiku loomisest, Eestiski on majandus- ja kommunikatsiooniministeeriumi eestvõttel sarnane kaksik loomisel (vt Eesti 3D kaksiku uuring). Siiski peab siinses kontekstis meeles pidama, et kui (meta)andmeid kasutatakse sotsiaalse/ kultuurilise/füüsilise reaalsuse modelleerimiseks, siis nende loodud mudelid jäljendavad, aga ka tõlgivad ja lihtsustavad ning on sellistena ebatäpsed ja paratamatult ka „valetavad”. Viitame siinkohal Umberto Eco (1977: 7) kuulsale väitele, et semiootika uurib kõike, mida saab kasutada valetamiseks. Nagu praeguseks on andmete kallutatuse (nt Milan, Treré 2019; Perez 2019) ja andmeõigluse (nt Heeks, Shekhar 2019; Dencik jt 2019) uuringute põhjal teada, siis andmed tõepoolest pahatihti eksitavad, toovad kaasa eri laadi ebaõiglust ja seeläbi ka uusi konflikte. Kultuurisemiootikal põhinevate andmeuuringute eriline hoiak selliste andmesuhete lahkamisel võiks olla, et kui valetamine on nii-öelda paratamatu, kui mis tahes representatsioonid, sealhulgas andmepõhised representatsioonid, on alati valikulised, kuna kujutavad reaalsusest vaid teatud osa, jättes muu kõrvale, siis tuleks keskenduda sellele, kuidas need valikud mõjutavad kultuuridünaamikat kultuuri eri tasanditel - nii mikro-, meso- kui ka makrokontekstides. Mikrokonteksti näitena tähendaks see küsimust sellest, kuidas metaandmete skeemid kindlates andmebaasides võivad mõjutada kasutajate saadavat ülevaadet ajaloosündmustest (Coleman 2020; Ibrus, Ojamaa 
2018); mesotasandil võivad andmekalded mõjutada näiteks rahvuskultuuride võrdlusi (Fischer, Poortinga 2018; Erlin jt 2021), makrotasandil aga üleilmseid kokkuvõtteid, milliseid teostab kõnekalt Lev Manovich (2020).

\section{Kultuuriandmete analüüs Tallinna Ülikoolis}

Kõiki eespool välja toodud aspekte arvesse võttes on võimalik esitada uudne süsteemne lähenemine kultuuriandmete analüüsile, mis liigub edasi digihumanitaaria problemaatikast, lópetab nn kahe kultuuri segregatsiooni ning kasutab ära kultuurisemiootika ja kompleksteaduse ühendamise potentsiaali. Nendest kindlaks tehtud sobivustest lähtudes saame välja pakkuda holistliku lähenemiste skaala, lastes ühelt poolt üksikutel teadlastel jääda oma spetsialiseerumise juurde, kuid võimaldades neil teiselt poolt osaleda süsteemselt loodud võrgustikes, mis püüavad kokku panna mitmetahulist, ent siiski integreeritud ettekujutust semiosfäärilisest dünaamikast.

Tallinna Ülikooli ERA (European Research Area) õppetooli projektis CUDAN (Cultural Data Analytics, vt Cudan Open Lab) rakendatakse seda visiooni praegu praktikas. Tuginedes osaliselt varasematele uurimistöödele, ${ }^{2}$ on eesmärk panna alus semiosfääri süsteemsele uurimisele, mis võib kultuurikäsitust muuta sama põhjalikult, kui süsteemibioloogia muutis arusaama elust. Näitena praegusest interdistsiplinaarsest tööst hõlmab CUDAN-i asjatundmine kultuurisemiootikat, kunstiajalugu, kultuuriajalugu, meediauuringuid, poliitikauuringuid, loomemajanduse uuringuid, haridustehnoloogiat, evolutsioonilist majandusteadust, võrguteadust, arvutuslikku sotsiaalteadust, arvutilingvistikat, masinõpet, kasutajakogemuse disaini, kultuurifüüsikat ja generatiivset kunsti. Tuues kokku sedavõrd erisugused meetodid ja uurimissuunad, kasutavad CUDAN-i teadlased kirevat allikmaterjali, mis hõlmab muu hulgas audiovisuaalseid, pildi-, teksti- ja arvandmeid, nii mittestruktureeritud kui ka struktureeritud andmeid andmebaaside ja graafide kujul, mille hulka kuuluvad avaandmed ning andmed avaliku ja erasektori partneritelt. Selle ettevõtmisega kaasnevad ilmselgelt riskid, aga ka suured võimalused. Raskus ja samas väga suur potentsiaal seisneb ühise süstemaatilise lähenemise loomises. Ent metodoloogilist riski on võimalik maandada, kui eri teadlased saavad pakkuda oma valdkonna põhjalikku tundmist ja samal ajal on neil võimalik valdkonnaülese koostöö toel minna kaugemale oma eriala piiridest.

Pakume välja, et sellist valdkonnaülest tööd tehes võib Eesti võtta rahvusvahelises teadusmaailmas süstemaatilise kultuuriteaduse juhtrolli, tuginedes seejuures nn Eesti teooria rikkalikule traditsioonile (Tamm, Kull 2016). See potentsiaal sarnaneb süsteemibioloogia kujunemisega, kus samaväärne kvalitatiivse ja kvantitatiivse uuri-

\footnotetext{
${ }^{2}$ Kõige olulisema eelkäija ja eeskujuna võib välja tuua kultuurianalüütika (ingl cultural analytics) uurimissuuna, millele Lev Manovich pani aluse 2007. aastal (vt ülevaatlikult Manovich 2020). Kui kultuurianalüütika rõhutab eelkõige koostööd arvutiteadustega ja panustab erinevatele arvutuslikele meetoditele, siis kultuuriandmete analüüs peab selle kõrval oluliseks kultuurisemiootilist lähenemist, komplekssete võrgustike analüüsi ja samuti koostööd loodusteadustega (eeskätt süsteemibioloogiaga).
} 
mise lõimimine viis edusammudeni eluprotsesside mõistmises ja tõi ühiskonnale kestvat kasu. Samamoodi võib meie uudne lähenemine kultuuriandmete analüüsile õige suunamise korral tasapisi jõudu koguda, olles lõpuks midagi enamat kui uudse terminoloogia põhine moeröögatus või lühiajaliselt rahastatud projekti piiratud tulem. Väidame, et õige tee on senisest integreeritum lähenemine kultuurianalüüsile, mis seisab kõrgemal kunstlikust nn kahe kultuuri lahutamisest. Meie lähenemise teoreetiline alus on kultuurisemiootika seni veel ebapiisavalt rakendatud potentsiaal (Hartley jt 2021a; Tamm, Torop, ilmumas) ja kultuuri kompleksteadus (Mitchell 2009; Schich jt 2014; Complexity Explained 2019). See tugineb ka nn kultuuriteaduse lähenemisele (Hartley, Potts 2014; Hartley 2020), kus on juba sarnase teoreetilise integreerimise vallas tööd tehtud. Empiiriliselt toetab meie lähenemist kasvav teadustööde hulk, mis ühendab kultuuriajaloo, võrgustike, kõrgema astme topoloogia ja arvutuslike meetodite võimalusi (Schich 2019).

Alates projekti CUDAN käivitamisest on kultuuriandmete analüüsi võtnud kasutusele üha suurem hulk maailma juhtivaid óppeasutusi. 2021. aastal korraldavad Carnegie Melloni ülikool ja Santa Fe instituut kultuuriandmete analüüsi kursuse. Ludwig Maximiliani ülikool Münchenis võttis selle nimetuse kasutusele uue teadusgrupi jaoks. California Berkeley ülikoolis on kultuuriandmete analüüs oluline andmeteadustesse tehtavate investeeringute osa. Kultuuriandmete analüüsi laadne teadustöö toimub samuti sellistes infoteaduste õppeasutustes nagu Indiana ülikool Bloomingtonis, Network Science Institute of Northeastern University Bostonis, Northwestern Institute on Complex Systems of Northwestern University Chicago lähedal ning KAIST Graduate School of Culture Technology Lõuna-Koreas. Kõigis neis ja mujalgi kasvab kultuuriandmete analüüs jõudsalt. Tallinna Ülikooli CUDAN-i Open Lab'i eesmärk on osaleda selles teedrajavas liikumises.

Artikli kirjutamist toetasid Eesti Teadusagentuuri grandid PRG1276 „Digitaalne Liivimaa: keskaja Liivimaa digiajalooline analüüs (u. 1200-1550)" ja PRG1191 „Kultuuri avaandmelahenduste avaliku väärtuse ahelad" ning Euroopa Liidu Horisont 2020 projekt CUDAN (grandi number 810961).

\section{VEEBIVARAD}

Complexity Explained. Manlio De Domenico, D. Brockmann, C. Camargo, C. Gershenson, D. Goldsmith, S. Jeschonnek, L. Kay, S. Nichele, J. R. Nicolás, T. Schmickl, M. Stella, J. Brandoff, A. J. Martínez Salinas, H. Sayama. 27. VI 2019. https://doi.org/10.17605/OSF. IO/TQGNW

Cudan Open Lab. https://cudan.tlu.ee

Eesti 3D kaksiku uuring. https://eehitus.ee/timeline-post/3d-kaksiku-uuring

What is Digital Humanities? https://whatisdigitalhumanities.com 
Ahnert, Ruth; Ahnert, Sebastian E.; Coleman, Catherine Nicole; Weingart, Scott B. 2021. The Network Turn: Changing Perspectives in the Humanities. Cambridge: Cambridge University Press. https://doi.org/10.1017/9781108866804

Anderson, Philip W. 1972. More is different. - Science, kd 177, nr 4047, lk 393-396. https:// doi.org/10.1126/science.177.4047.393

Balkun, Mary McAleer; Deyrup, Marta Mestrovic (toim) 2020. Transformative Digital Humanities: Challenges and Opportunities. London-New York: Routledge. https://doi. org/10.4324/9780429399923

Barabási, Albert-László 2016. Network Science. Cambridge: Cambridge University Press.

Barthelemy, Marc 2019. The statistical physics of cities. - Nature Reviews Physics, kd 1, nr 6, lk 406-415. https://doi.org/10.1038/s42254-019-0054-2

Benington, John; Moore, Mark H. 2011. Public Value: Theory and Practice. London: Palgrave Macmillan.

Berry, David M. 2014. Critical Theory and the Digital. London: Bloomsbury Academic.

Berry, David M.; Fagerjord, Anders 2017. Digital Humanities: Knowledge and Critique in a Digital Age. Cambridge: Polity.

Bertalanffy, Ludwig von 1951. General system theory: A new approach to unity of science. Human Biology, kd 23, nr 4, lk 302-312.

Bod, Rens 2014. A New History of the Humanities. Oxford: Oxford University Press.

Cassirer, Ernst 2000 [1910]. Substanzbegriff und Funktionsbegriff. - E. Cassirer, Gesammelte Werke. Toim Birgit Recki. Hamburg: Felix Meiner Verlag.

Coleman, Catherine Nicole 2020. Managing bias when library collections become data. - International Journal of Librarianship, kd 5, nr 1, lk 8-19. https://doi.org/10.23974/ ijol.2020.vol5.1.162

Couldry, Nick; Mejias, Ulises A. 2019. The Costs of Connection: How Data is Colonizing Human Life and Appropriating for Capitalism. Stanford: Stanford University Press. https://doi.org/10.1515/9781503609754

Dencik, Lina; Hintz, Arne; Redden, Joanna; Treré, Emiliano 2019. Exploring data justice: Conceptions, applications and directions. - Information, Communication \& Society, kd 22, nr 7, lk 873-881. https://doi.org/10.1080/1369118X.2019.1606268

Dilthey, Wilhelm 1959 [1883]. Gesammelte Schriften. Kd 1. Stuttgart: Teubner.

Dilthey, Wilhelm 1997. Ajaloolise maailma ülesehitus vaimuteadustes. - Filosoofilise hermeneutika klassikat. (Avatud Eesti raamat.) Tlk Andrus Tool. Tartu: Ilmamaa, lk 72-83.

Eco, Umberto 1977. A Theory of Semiotics. Bloomington: Indiana University Press.

Engelbrecht, Jüri; Kitt, Robert 2020. Komplekssüsteemid ehk Tervik on suurem kui osade summa. Tallinn: Postimees Kirjastus.

Erlin, Matt; Piper, Andrew; Knox, Douglas; Pentecost, Stephen; Drouillard, Michaela; Powell, Brian; Townson, Cienna 2021. Cultural capitals: Modeling 'Minor' European literature. Journal of Cultural Analytics, nr 2, lk 40-73. https://doi.org/10.22148/001c.21182

Fischer, Ronald; Poortinga, Ype H. 2018. Addressing methodological challenges in culturecomparative research. - Journal of Cross-Cultural Psychology, kd 49, nr 5, lk 691-712. https://doi.org/10.1177/0022022117738086 
Gold, Matthew K. (toim) 2012. Debates in the Digital Humanities. London-Minneapolis: University of Minnesota Press.

Gold, Matthew K.; Klein, Lauren F. (toim) 2016. Debates in the Digital Humanities 2016. London-Minneapolis: University of Minnesota Press.

Gold, Matthew K.; Klein, Lauren F. (toim) 2019. Debates in the Digital Humanities 2019. London-Minneapolis: University of Minnesota Press.

Hartley, John 2009. From Cultural Studies to Cultural Science. - Cultural Science, kd 2, nr 1, lk 1-16. https://doi.org/10.5334/csci.18

Hartley, John 2020. How We Use Stories and Why That Matters: Cultural Science in Action. New York: Bloomsbury. https://doi.org/10.5040/9781501351662

Hartley, John; Ibrus, Indrek; Ojamaa, Maarja 2021a. On the Digital Semiosphere: Culture, Media and Science for the Anthropocene. London: Bloomsbury. https://doi. org/10.5040/9781501369209

Hartley, John; Ibrus, Indrek; Ojamaa, Maarja 2021b. Emergent self-mediating classes in the digital semiosphere: Coronavirus conspiracies and climate justice movement. - Nordic Journal of Cultural Studies, kd 3, nr 1, lk 118-140. https://doi.org/10.2478/njms-20210007

Hartley, John; Potts, Jason 2014. Cultural Science: A Natural History of Stories, Demes, Knowledge and Innovation. London: Bloomsbury.

Heeks, Richard; Shekhar, Satyarupa 2019. Datafication, development and marginalised urban communities: An applied data justice framework. - Information, Communication \& Society, kd 22, nr 7, lk 992-1011. https://doi.org/10.1080/1369118X.2019.1599039

Hexter, Jack H. 1972. Fernand Braudel and the Monde Braudellien... - Journal of Modern History, kd 44, nr 4, lk 480-539. https://doi.org/10.1086/240839

Huxley, T. 1869. Nature: Aphorisms by Goethe. - Nature, kd 1, lk 9-11. https://doi. org/10.1038/001009a0

Ibrus, Indrek; Ojamaa, Maarja 2018. Newsreels versus newspapers versus metadata: A comparative study of metadata modelling the 1930s in Estonia. - VIEW: Journal of European Television History and Culture, kd 7, nr 14, lk 123-137. https://doi.org/10.18146/22130969.2018.jethc157

Ibrus, Indrek; Ojamaa, Maarja 2020. The creativity of digital (audiovisual) archives: A dialogue between media archaeology and cultural semiotics. - Theory, Culture \& Society, kd 37, nr 3, lk 49-70. https://doi.org/10.1177/0263276419871646

Isaak, Jim; Hanna, Mina J. 2018. User data privacy: Facebook, Cambridge Analytica, and privacy protection. - Computer, $\mathrm{kd} \mathrm{51,} \mathrm{nr} \mathrm{8,} \mathrm{lk} \mathrm{56-59.} \mathrm{https://doi.org/10.1109/}$ MC.2018.3191268

Jacobs, Jane 1961. The Death and Life of Great American Cities. New York: Vintage Books. Jones, Steven E. 2014. The Emergence of the Digital Humanities. London-New York: Routledge.

Kirschenbaum, Matthew G. 2012. Digital humanities as/is a tactical turn. - Debates in the Digital Humanities. Toim Matthew K. Gold. Minneapolis: University of Minnesota Press, lk 415-428. https://doi.org/10.5749/minnesota/9780816677948.003.0043

Kittler, Friedrich A. 1994. Wenn die Freiheit wirklich existiert, dann soll sie doch ausbrechen. - Am Ende vorbei. Toim Rudolf Maresch. Wien: Turia \& Kant, lk 95-129. 
Kull, Kalevi 1998. On semiosis, Umwelt, and semiosphere. - Semiotica, kd 120, nr 3-4, lk 299-310.

Kull, Kalevi; Lotman, Mihhail 1995. Semiotica Tartuensis: Jakob von Uexküll ja Juri Lotman. - Akadeemia, nr 12, lk 2467-2483.

Kull, Kalevi; Lotman, Mihhail 2012. Semiotica Tartuensis: Jakob von Uexküll and Juri Lotman. - Chinese Semiotic Studies, kd 6, nr 1, lk 312-323. https://doi.org/10.1515/css-2012-0122

Lee, Minjin; Barbosa, Hugo; Youn, Hyejin; Holme, Petter; Ghoshal, Gourab 2017. Morphology of travel routes and the organization of cities. - Nature Communications, $\mathrm{kd} 8, \mathrm{nr} 1$, lk 1-10. https://doi.org/10.1038/s41467-017-02374-7

Mandelbrot, Benoit 1982. The Fractal Geometry of Nature. Kd 1. New York: WH Freeman.

Manovich, Lev 2020. Cultural Analytics. Cambridge, Massachusetts: MIT Press. https://doi. org/10.7551/mitpress/11214.001.0001

Mazzucato, Mariana 2018. The Value of Everything: Making and Taking in the Global Economy. London: Allen Lane.

Milan, Stefania; Treré, Emiliano 2019. Big Data from the South(s): Beyond data universalism. - Television \& New Media, kd 20, nr 4, lk 319-335. https://doi. org/10.1177/1527476419837739

Mitchell, Melanie 2009. Complexity: A Guided Tour. Oxford: Oxford University Press.

Perez, Caroline Criado 2019. Invisible Women: Exposing Data Bias in a World Designed for Men. London: Chatto \& Windus.

Pressner, Todd; Schnapp, Jeffrey 2009. The Digital Humanities Manifesto 2.0. http://manifesto.humanities.ucla.edu/2009/05/29/the-digital-humanities-manifesto-20

Prigogine, llya; Stengers, Isabelle 2018 [1984]. Order Out of Chaos: Man's New Dialogue with Nature. London: Verso Books.

Ravenstein, Ernest George 1885. The laws of migration. - Journal of the Statistical Society of London, kd 48, nr 2, lk 167-235. https://doi.org/10.2307/2979181

Riedl, Rupert 2000. Strukturen der Komplexität: Eine Morphologie des Erkennens und Erklärens. Berlin: Springer. https://doi.org/10.1007/978-3-642-56946-3

Schich, Maximilian 2016. Figuring out art history. - International Journal for Digital Art History, nr 2, lk 41-67.

Schich, Maximilian 2019. Cultural Analysis Situs. ART-Dok eprint.

Schich, Maximilian; Song, Chaoming; Ahn, Yong-Yeol; Mirsky, Alexander; Martino, Mauro; Barabási, Albert-László; Helbing, Dirk 2014. A network framework of cultural history. Science, kd 345, nr 6196, lk 558-562. https://doi.org/10.1126/science.1240064

Schich, Maximilian; Meirelles, Isabel; Malina, Roger (toim) 2016. Arts, Humanities, and Complex Networks. 5. vlj [Kindle Edition]. Cambridge: MIT Press.

Schreibman, Susan; Siemens, Ray; Unsworth, John (toim) 2004. A Companion to Digital Humanities. Malden, MA-Oxford: Blackwell.

Schreibman, Susan; Siemens, Ray; Unsworth, John (toim) 2016. A New Companion to Digital Humanities. Malden, MA-Oxford: Wiley. https://doi.org/10.1002/9781118680605

Shuttleworth, Alan 1966. Two Working Papers in Cultural Studies - A Humane Culture and Max Weber and the „Cultural Sciences”. Birmingham: Centre for Contemporary Cultural Studies, University of Birmingham. 
Smithies, James 2017. The Digital Humanities and the Digital Modern. London: Palgrave Macmillan. https://doi.org/10.1057/978-1-137-49944-8

Snow, Charles Percy 2017 [1961]. Kaks kultuuri ja teadusrevolutsioon. - C. P. Snow, Kaks kultuuri ja teadusrevolutsioon. Jerome Kagan, Kolm kultuuri. Loodusteadused, sotsiaalteadused ja humanitaarteadused 21. sajandil. (Avatud Eesti raamat.) Tlk Mart Trummal. Tartu: Tartu Ülikooli Kirjastus, lk 11-56.

Svensson, Patrik 2012. Beyond the Big Tent. - Debates in the Digital Humanities. Toim Matthew K. Gold. Minneapolis: University of Minnesota Press, lk 36-49. https://doi. org/10.5749/minnesota/9780816677948.003.0004

Zinoviev, Dmitry 2016. The pain of complexity. - Leonardo, kd 49, nr 5, lk 450. https://doi. org/10.1162/LEON_a_01271

Tamm, Marek; Kull, Kalevi 2016. Toward a reterritorialisation of cultural theory: Estonian theory from Baer via Uexküll to Lotman. - History of the Human Sciences, kd 29, nr 1, lk 75-98. https://doi.org/10.1177/0952695115617407

Tamm, Marek; Torop, Peeter (toim) (ilmumas). The Companion to Juri Lotman: A Semiotic Theory of Culture. London: Bloomsbury.

Terras, Melissa; Nyhan, Julianne; Vanhoutte, Edward (toim) 2013. Defining Digital Humanities: A Reader. Farnham: Ashgate.

Torop, Peeter 2008. Translation as communication and auto-communication. - Sign Systems Studies, kd 36, nr 2, lk 375-397. https://doi.org/10.12697/SSS.2008.36.2.06

Torop, Peeter 2015. Kultuuriteooria kui kultuuri eneseteadvus. - Akadeemia, nr 4, lk 626649.

Uexküll Jakob von 1909. Umwelt und Innenwelt der Tiere. Berlin: J. Springer.

Uexküll, Jakob von 2012. Omailmad. (Eesti mõttelugu 105.) Koost Kalevi Kull, Riin Magnus. Tlk Mari Tarvas, Krista Räni. Tartu: Ilmamaa.

Weaver, Warren 1948. Science and complexity. - American Scientist, kd 36, lk 536-567.

Weingart, Scott B.; Eichmann-Kalwara, Nickoal 2017. What's under the Big Tent?: A study of ADHO conference abstracts. - Digital Studies/Le Champ Numérique, kd 7, nr 1. https:// doi.org/10.16995/dscn.284

Williams, Raymond 1974. Communications as cultural science. - Journal of Communication, kd 24, nr 3, lk 17-26. https://doi.org/10.1111/j.1460-2466.1974.tb00385.x

Windelband, Wilhelm 1993 [1894]. Ajalugu ja loodusteadus. Tlk Marju Luts. - Akadeemia, nr 3, lk 490-505.

Winthrop-Young, Geoffrey 2000. Silicon sociology, or, Two kings on Hegel's throne? Kittler, Luhmann, and posthuman merger of German media theory. - The Yale Journal of Criticism, kd 13, nr 2, lk 391-420. https://doi.org/10.1353/yale.2000.0027

Indrek Ibrus (snd 1974), PhD, Tallinna Ülikooli Balti filmi, meedia ja kunstide instituudi meediainnovatsiooni professor (Narva mnt 27, 10120 Tallinn), indrek.ibrus@tlu.ee

Maximilian Schich (snd 1974), PhD, Tallinna Ülikooli Balti filmi, meedia ja kunstide instituudi kultuuriandmete analüüsi sihtrahastusega professor (Narva mnt 27, 10120 Tallinn), mxs@tlu.ee 
Marek Tamm (snd 1973), PhD, Tallinna Ülikooli humanitaarteaduste instituudi kultuuriajaloo professor (Narva mnt 29, 10120 Tallinn), marek.tamm@tlu.ee

\section{From digital humanities to cultural data analytics}

Keywords: cultural data analytics, cultural analytics, digital humanities, complexity, semiosphere, cultural semiotics, cultural science

Digital Humanities (DH) has been a success story in the academic world over the last twenty years which has opened many new vistas in the humanities research. However, we argue that it is better to consider DH as a transitory phenomenon that needs to be developed into more specific research fields in order to overcome some fundamental shortcomings of DH. First, it is vital to transcend the division between qualitative inquiry into ideographic phenomena and quantification of nomothetic phenomena. This specifically includes the emergence and analysis of organized complexity, which emerges right in between. Secondly, it is important to surpass the dichotomy of singular and general as research objects and replace this by the notion of semiosphere as a research object, defined as the "smallest" functioning element of culture by Juri Lotman. From this perspective, the singular cultural unit is always conditioned by the whole of the semiosphere, but the whole can be always changed by the singular unit. Thirdly, the denominator "digital" is questionable and needs to be left behind, as there are many other forms of computation, which can be analog and/or digital. Indeed, alternative forms of non-digital computation are already seeing a comeback. Fourthly, the label of "humanities" is at the same time too large and too restrictive. We would argue for a more specific study of meaning making practices in human society, yet without confining ourselves to traditional humanities scholarship but learning from the new developments in system biology, evolutionary economics, complexity science and many more. We propose to call this new transdisciplinary field of study "cultural data analytics", aiming to explore the dynamics of meaning making practices by computational means and looking at a spectrum of materials (textual, sonic, visual, multimodal, etc.) both regarding the longue durée and in real time, if not anticipating the future.

Indrek Ibrus (b. 1974), PhD, Tallinn University, Baltic Film, Media, and Arts School, Professor of Media Innovation (Narva mnt 27, 10120 Tallinn), indrek.ibrus@tlu.ee

Maximilian Schich (b. 1974), PhD, Tallinn University, Baltic Film, Media, and Arts School, Research Professor of Cultural Data Analytics (ERA Chair) (Narva mnt 27, 10120 Tallinn), mxs@tlu.ee

Marek Tamm (b. 1973), PhD, Tallinn University, School of Humanities, Professor of Cultural History (Narva mnt 29, 10120 Tallinn), marek.tamm@tlu.ee 